\title{
The application of isodromic equation for calculation of PID-controller integrated component
}

A functional feature of the application of electronics used for the automatic control of internal combustion engines is necessity in the proportional conversion of ECU electrical signals into the mechanical processes based on corresponding elements motion. For such conversion of information actuating mechanisms are used, referred as actuators. Actuators in the form of electrical machines (stepper or precision electric motors) or electric apparatuses (electromagnets and solenoids) are the mostly widespread in ICE. As a physical object of the research, the unit of Heinzmann, model StG 6-02V that is based on a DC electric drive controlled by a pulse-width modulation signal, was selected in the current work. It has a toothed gearbox and a non-contact reverse positional connection. This actuator provides an output torque of $6 \mathrm{Nm}$ and 36-degree range of output shaft rotational angle. The functional scheme of the electronic system of automatic control of a diesel engine based on mentioned device is developed. The PID regulator with feedback is used to control the actuator. A design formula that can be incorporated in the controller algorithm to calculate the integral component of the PID regulator was also obtained. Values of empirical coefficients were determined in this formula. The results of experimental confirmation of the correctness of the approach taken are presented. Thus, the new formula for determining the integral component of the PID regulator differs positively from the well-known solutions because the new approach is free from storing the whole array of previous data with discrepancy in the controller's RAM, that simplifies the application of the developed algorithm greatly and speeds up the computational capability of the controller.

Key words: diesel, automatic regulation, electronic system, control algorithm, PID regulator

\section{Introduction}

A functional feature of the application of electronics in internal combustion engines for their automatic control is the necessity of the proportional transformation of electrical signals of the electronic control unit into the mechanical processes of moving the corresponding elements. For such information transformation, so-called final controlling drive (FCD) also known as actuators, are used [1].

FCD (actuators) became the most widespread in ICE. These are electric machines (step or precision electric motors) or electric apparatuses (electromagnets and solenoids) of different kinds.

As a physical object, the actuator Heinzmann, model StG 6-02V was used in the current research. This model is based on a DC motor drive controlled by a Pulse-Width Modulation (PWM) signal.
It has a toothed gearbox and a non-contact reverse positional connection. This actuator provides an output torque of $6 \mathrm{Nm}$ and a range for output shaft rotation angle of $36^{\circ}$ [2].

The functional scheme of the developed electronic system of the diesel engine automatic control (DEAC) is presented in Fig. 1. The external and internal variables of DEAC are: $\mathrm{X}$ - current position of the engine control unit, $\mathrm{n}$ - current crankshaft rotation speed, $\mathrm{Hp}$ - position of the fuel supply control element (high pressure fuel pump (HPFP) rail position), $\mathrm{f}-$ the relative magnitude of the PWM signal. The FCD governor is a part of the ECU engine program. Detailed description of the algorithm of operation of the subsystem developed for the control of the drive positioning is given in the article [3].



Fig. 1. Functional diagram of the electronic control system of a diesel engine [3] 


\section{Theoretical study}

\subsection{A brief description of the algorithm}

Taking into account the availability of a reverse positional feedback due to the current HPFP position, the value of "discrepancy" could be calculated:

$$
\Delta \mathrm{Hp}=\mathrm{Hp}-\mathrm{Hp}_{0}
$$

The developed FCD algorithm is based on the parallel work of positional $(\mathrm{P})$ and proportional-integral-derivative (PID) controllers (see Fig. 1).

In this case, the P-controller is a non-inertial amplifier that determines the required level of filling the PWM signal to achieve a given equilibrium position of the rails $\mathrm{Hp}_{0}$. Its equation has a form:

$$
\mathrm{f}_{0}=\mathrm{K} \cdot \mathrm{Hp}_{0}
$$

PID-controller operates in parallel to P-controller and on the basis of the magnitude of the discrepancy, determined by the formula (1), accelerates the achievement of a given position of $\mathrm{Hp}_{0}$ by means of the program realization of the expression:

$$
\Delta \mathrm{f}=\mathrm{K}_{\mathrm{D}} \cdot \Delta^{2} \mathrm{Hp}+\mathrm{K}_{\mathrm{P}} \cdot \Delta \mathrm{Hp}+\mathrm{K}_{\mathrm{I}} \cdot \mathrm{S}
$$

Thus, PWM signal that is sent to the executive mechanism has the following meaning:

$$
\mathrm{f}=\mathrm{f}_{0}+\Delta \mathrm{f}
$$

By analyzing equations (2) and (3), it is not difficult to notice that the first of them provides the static characteristics, and the second determines the dynamic properties of the system.

The differential component in expression (3) is defined as:

$$
\Delta^{2} \mathrm{Hp}=\Delta \mathrm{Hp}(\mathrm{t})-\Delta \mathrm{Hp}(\mathrm{t}-\mathrm{T})
$$

where $T=120 / n-$ clock design period, which depends on the current crankshaft speed $\mathrm{n}$ and determines the time constant for integration and differentiation.

\subsection{An alternative definition of the integral component}

The third component in the equation (3) $\mathrm{K}_{\mathrm{I}} \cdot \mathrm{S}$ defines the integral feedback effect on the PWM control. It is the product of some constant $K_{I}$ to the finite sum of the discrepancy S.

For the mathematical determination of the current $S(t)$ value, the differential equation of the ideal integral link with the transfer coefficient equal to 1 can be used (or it can be regarded as the coefficient $\mathrm{K}_{\mathrm{I}}$ ) [4]:

$$
\frac{\mathrm{S}^{\prime}(\mathrm{t})}{\mathrm{dt}}=\Delta \mathrm{Hp}(\mathrm{t})
$$

which connects input and output signals: $H p(t)$ and $S^{\prime}(t)$ accordingly.

The numerical solution of this differential equation can be represented in the form of a finite sum, provided that the periodicity of the registration of the irregularity and the limitation of the time (number) of the last irregular registrations is constant

$$
\mathrm{S}^{\prime}(\mathrm{t}) \approx \sum_{\mathrm{i}=0}^{\mathrm{N}-1} \Delta \mathrm{Hp}(\mathrm{t}-\mathrm{iT})
$$

here $\mathrm{N}$ is number of terms in the final sum (the number of recent registrations).

For the simplification of the constant values condition in discrepancy, during all integration time it is accepted $\Delta \mathrm{Hp}(\mathrm{t})$ $=\Delta \mathrm{Hp}(\mathrm{t}-\mathrm{iT})=\ldots=\Delta \mathrm{Hp}(\mathrm{t}-\mathrm{NT})=$ const.

Then the limit of this sum will be equal:

$$
\lim _{\mathrm{t} \rightarrow \mathrm{N} \cdot \mathrm{T}} \mathrm{S}^{\prime}(\mathrm{t})=\lim _{\mathrm{i} \rightarrow \mathrm{N}}\left[\sum_{\mathrm{i}=0}^{\mathrm{N}-1} \Delta \mathrm{Hp}(\mathrm{t}-\mathrm{iT})\right]=\mathrm{N} \cdot \Delta \mathrm{Hp}(\mathrm{t})
$$

Equation (6) is an algorithmic-calculated and can be used to determine the third component in equation (3). But its significant disadvantage for practical use in the algorithm is that for calculations it is necessary to have an array of the last $\mathrm{N}$ values of the discrepancy, which additionally overloads the controller RAM and reduces processor speed. An alternative approach to defining an integral component in the algorithm of the electronic PID controller is proposed in this study to eliminate this disadvantage.

To determine the same sum for the integral component $\mathrm{S}(\mathrm{t})$, the differential equation of the isodromic link is used [4]:

$$
\frac{\mathrm{S}(\mathrm{t})}{\mathrm{dt}}=\mathrm{k} \cdot \Delta \mathrm{Hp}(\mathrm{t})+\mathrm{k}_{1} \frac{\mathrm{d} \Delta \mathrm{Hp}(\mathrm{t})}{\mathrm{dt}} .
$$

The coefficients $\mathrm{k}$ and $\mathrm{k}_{1}$ in the differential equation have the following physical meaning: $\mathrm{k}-$ the transmission factor (amplification), and $\mathrm{k}_{1} / \mathrm{k}=\mathrm{T}_{\mathrm{I}}$ - time constants of the isodrome [4].

After integrating this differential equation, an expression is obtained (the integral action is replaced by the action of the final summation):

$$
\mathrm{S}(\mathrm{t})=\mathrm{k} \sum_{0}^{\mathrm{t}} \Delta \mathrm{Hp}(\mathrm{t})+\mathrm{k}_{1} \Delta \mathrm{Hp}(\mathrm{t})
$$

Taking into account the recurrence $S^{\prime}(t)=\sum_{0}^{t} \Delta H p(t)=$ $\mathrm{S}^{\prime}(\mathrm{t}-\mathrm{T})+\Delta \mathrm{Hp}(\mathrm{t})$ and proceeding from the fact that at each moment of time the following condition must be fulfilled $S(t)=S^{\prime}(t)$, and after a simple transformation and designation $\mathrm{K}_{\mathrm{I}}=\mathrm{k}_{1}+\mathrm{k}$ the expression could be written as:

$$
\mathrm{S}(\mathrm{t})=\mathrm{k} \cdot \mathrm{S}(\mathrm{t}-\mathrm{T})+\mathrm{K}_{\mathrm{I}} \cdot \Delta \mathrm{Hp}(\mathrm{t})
$$

The resulting equation (8) is a design formula and can be included in the controller algorithm instead of equation (6). Moreover, it devoids the deficiencies of equation (6) because it does not contain the action of the final summation and does not require constant storage of the array of the last discrepancy values. However, equation (8) has uncertain coefficients in the form of coefficients $\mathrm{K}_{\mathrm{I}}$ and $\mathrm{k}$.

\subsection{Determination of the key coefficients}

Determination of the values of constants $\mathrm{K}_{\mathrm{I}}$ and $\mathrm{k}$ is based on the statement that the boundary of the sum found by equation (6) and equation (8) must coincide. For this condition, the equation (8) must be transformed into the form of an infinite integral sum:

$$
\mathrm{S}(\mathrm{t})=\mathrm{K}_{\mathrm{I}} \sum_{\mathrm{i}=0}^{\infty}\left[\mathrm{k}^{\mathrm{i}} \cdot \Delta \mathrm{Hp}(\mathrm{t}-\mathrm{iT})\right]
$$

The expression (9) is identical to equation (8), but more complex in practical use. However, the analysis of this equation shows that the coefficient $\mathrm{K}_{\mathrm{I}}$ can be attributed to the coefficient $\mathrm{K}_{\mathrm{I}}$. Thus, it was established that $\mathrm{K}_{\mathrm{I}}=1$. 
The limit of the sum received by (9) at $\mathrm{k}<1$ :

$$
\begin{aligned}
& \lim _{\mathrm{t} \rightarrow \infty} \mathrm{S}(\mathrm{t})=\lim _{\mathrm{t} \rightarrow \infty}\left(\mathrm{K}_{\mathrm{I}} \sum_{\mathrm{i}=0}^{\mathrm{n}}\left[\mathrm{k}^{\mathrm{i}} \cdot \Delta \mathrm{Hp}(\mathrm{t}-\mathrm{iT})\right]\right)= \\
& =\Delta \mathrm{Hp}(\mathrm{t}) \cdot \lim _{\mathrm{n} \rightarrow \infty}\left[\sum_{\mathrm{i}=0}^{\mathrm{n}} \mathrm{k}^{\mathrm{i}}\right]=\Delta \mathrm{Hp}(\mathrm{t}) \cdot \frac{1}{1-\mathrm{k}}
\end{aligned}
$$

Here factors $\mathrm{K}_{\mathrm{I}}=1$ and $\Delta \mathrm{Hp}(\mathrm{t}-\mathrm{iT})=\Delta \mathrm{Hp}(\mathrm{t})-$ are the constants that can be taken as a boundary sign. From the condition of equality of sum of limits $\lim _{\mathrm{t} \rightarrow \mathrm{N} \cdot \mathrm{T}} \mathrm{S}^{\prime}(\mathrm{t})=$ $\lim _{t \rightarrow \infty} S(t)$, determined by the "integral" (6) and "isodromic" (8) methods, it can be written:

$$
\mathrm{N} \cdot \Delta \mathrm{Hp}(\mathrm{t})=\Delta \mathrm{Hp}(\mathrm{t}) \frac{1}{1-\mathrm{k}} .
$$

Hence, the value of the coefficient $\mathrm{k}$ in the form of a function from $\mathrm{N}$ :

$$
\mathrm{k}=1-\frac{1}{\mathrm{~N}}
$$

Possible values of the isodromic coefficient $\mathrm{k}$ in the restricted interval $\mathrm{N}=2 \ldots 100$ are graphically represented in Fig. 2.

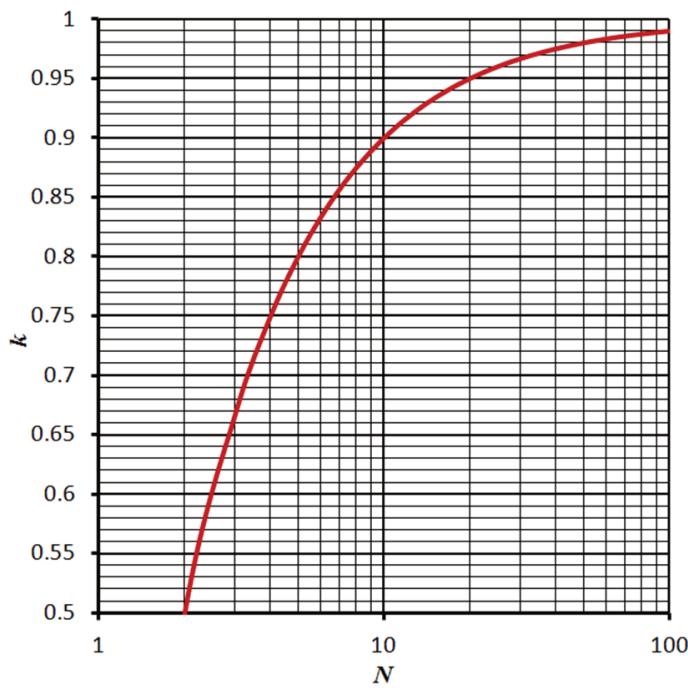

Fig. 2. Possible values of the isodromic coefficient $k$

It should be noted that the nomogram presented in Fig. 2 is used only for the previous choice of the constant coefficients values. The final value, undoubtedly, is determined in the process of PID-controller adjustment and taking into account the physical properties of the control system in general and the executive mechanism characteristics in particular.

\section{Experimental validation}

The results of experimental confirmation of the theoretical foundations are presented in Fig. 3 and Fig. 4. The experiment was carried out using the experimental setup described in [5]. During the experiment the microcontroller program determined the value of the isodromic coefficient as $\mathrm{k}=0.9(\mathrm{~N}=10)$.

Figure 3 shows the transient process, which is the reaction of the system (Fig. 1) on the external effect in the form of an artificial sharp change in the $\mathrm{Hp}_{0}$ setting ( $\Delta \mathrm{Hp}$ discrepancy) by $50 \%$ of the initial value. As it can be seen from Fig. 3, the law of the push $\mathrm{F}$ change (torque on the output lever of the actuator) using the proposed "isodromic" method qualitatively differs from the use of the traditional "integral" method - it passes faster at the beginning of the transient process and more smoothly at its end.

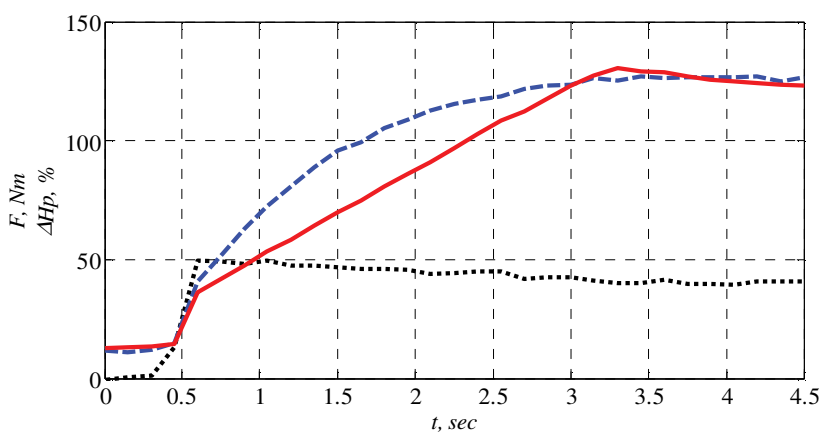

Fig. 3. Discrepancy $\Delta \mathrm{Hp}(\ldots .$.$) and push \mathrm{F}$ on the output lever: -_- "integral" method; - - - "isodromic" method

Additionally it can be illustrated by the rate of change in push during transient process, which in physical sense is the derivative of $\mathrm{dF} / \mathrm{dt}$ that is shown in Fig. 4. It can be also seen from the chart that in the case of "isodromic" method, the transient process is finished for 1.5 seconds earlier and has no overregulation. It has, undoubtedly, a positive impact on increasing the stability and operation speed of the entire automatic control system.

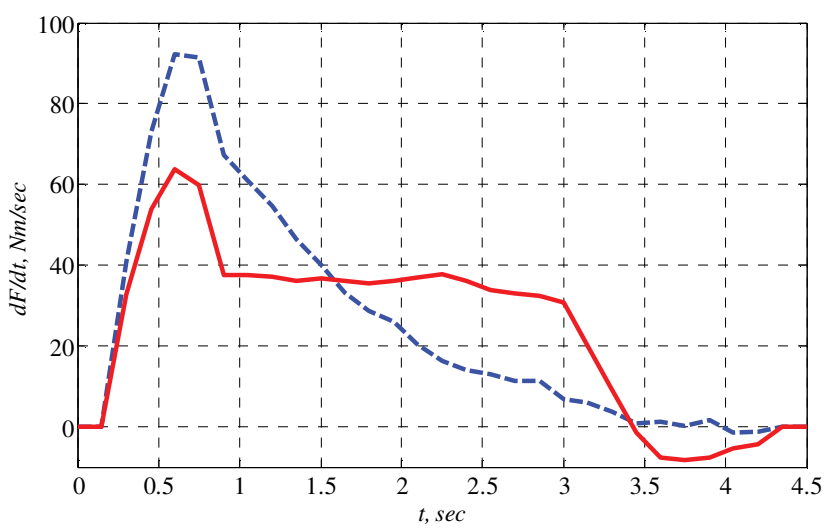

Fig. 4. Rate of the push change at the output lever: -_- "integral" method; - . - "isodromic" method

\section{Conclusions}

Thus, in the current research the new equation was offered for determining the integral component of the PIDcontroller. It is beneficially different from the traditional algorithm by "integral" method because there is no need to store the array of previous data in the memory of the controller that would significantly simplify the application of algorithm and speeds up the computational capability of the controller.

In addition, such an innovation in the actuator control methods would increase its maximum effort on the input lever by $50 \%$ and allow to accelerate the transient process for 1.5 seconds. 


\section{Nomenclature}

PWM Pulse-Width Modulation

PID Proportional-Integral-Derivative

ECU electronic control unit

$\mathrm{P}$ positional
FCD final controlling drive

DEAC diesel engine automatic control

HPFP high pressure fuel pump

\section{Bibliography}

[1] DORF, R.C., BISHOP, R.H. Modern control systems. 11th Edition. - Pearson International Edition. 2008, 1048.

[2] Heinzmann Actuators - [cited 08.03.2019] - Access: https://www.heinzmann.com/en/engine-and-turbinemanagement/actuator/electric.

[3] PROKHORENKO, A., SAMOILENKO, D., ORLINSKI, P. et al. Subsystem of positioning the actuator for an electronic diesel control system. Journal of Machine Construction and Maintenance. 2018, 1(108), 103-109.

Andriy Prokhorenko, DSc., DEng. - Department of Internal Combustion Engines, National Technical University "Kharkiv Polytechnic Institute".

e-mail:prokhorenko@kpi.kharkov.ua

Dmytro Samoilenko, DEng. - Faculty of Automotive and Construction Machinery Engineering, Warsaw University of Technology.

e-mail:dmytro.samoilenko@pw.edu.pl
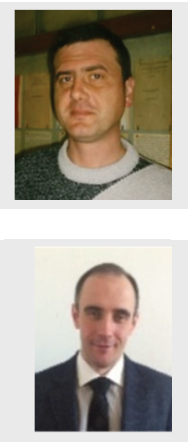

Serhii Kravchenko, DEng. - Department of Internal Combustion Engines, National Technical University "Kharkiv Polytechnic Institute".

e-mail: kravc4enkoserg@gmail.com
[4] БЕСЕКЕРСКИЙ, В.А., ПОПОВ, Е.П. Теория систем автоматического регулирования. М. Наука. 1975, 768.

[5] ПРОХОРЕНКО, А.О., КРАВЧЕНКО, С.С., САМОЙЛЕНКО Д.С. и дг. Універсальний електронний регулятор дизеля на основі електричного сервоактуатора. Двигатели внутреннего сгорания. Харьков: НТУ «ХПИ», 2018, 1, 31-39.

Piotr Orliński, DSc., DEng. - Faculty of Automotive and Construction Machinery Engineering, Warsaw University of Technology.

e-mail: piotr.orlinski@pw.edu.pl

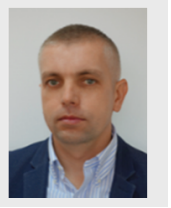

Dmytro Talanin - Department of Internal Combus-

tion Engines, National Technical University

"Kharkiv Polytechnic Institute".

e-mail: dima.kharkiv75@ukr.net
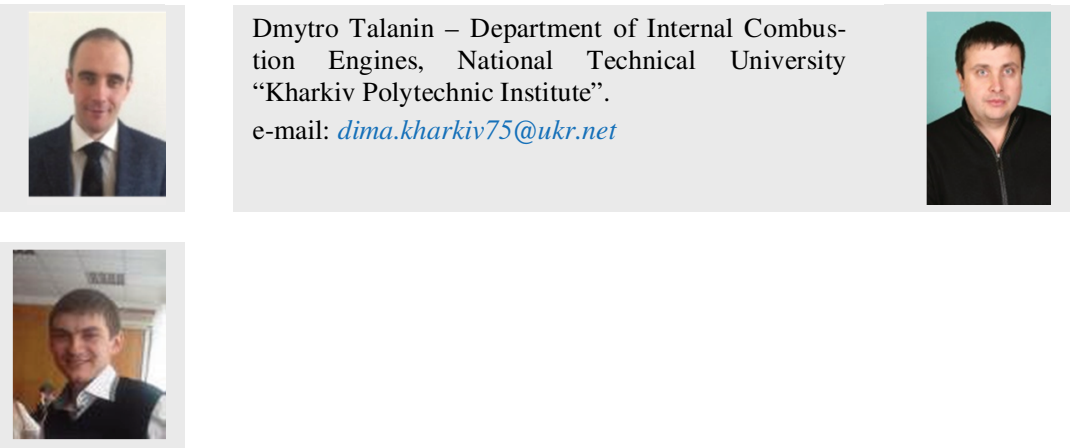